\title{
Selective Determination of Copper(II) Based on Cu(II)-Metal- Organic Framework in different Water Samples
}

\author{
Ehab S. Gad ${ }^{1,2^{*}}$, Tamer Awad Ali ${ }^{3}$,Amr A-E.Elsayed ${ }^{2}$, Gehad G. Mohamed ${ }^{4}$, H. A. El-Bary ${ }^{2}$ \\ ${ }^{1}$ Chemistry Department, College of Science and Arts, Jouf University, Saudi Arabia \\ ${ }^{2}$ Chemistry Department, Faculty of Science, Al-Azhar University, 11965 Cairo, Egypt. \\ ${ }^{3}$ Egyptian Petroleum Research Institute (EPRI), 11727, Cairo, Egypt. \\ ${ }^{4}$ Chemistry Department, Faculty of Science, Cairo University, 12613, Giza, Egypt. \\ *E-mail: e_said56@yahoo.com
}

doi: $10.20964 / 2020.12 .21$

Received: 25 July 2020/ Accepted: 13 September 2020 / Published: 31 October 2020

Four new modified electrodes are carbon pasted (o-NPOE; electrode I and DOS; electrode II); and screen-printed electrodes (o-NPOE; electrode III and DOS; electrode IV) based on Cu(II)-metalorganic framework ionophore were constructed for determination of copper ion $(\mathrm{Cu}(\mathrm{II}))$ over wide concentration ranges. The prepared electrodes exhibit Nernstian slope of $28.81 \pm 0.31,29.43 \pm 0.74$, $29.61 \pm 0.20$ and $30.04 \pm 0.22 \mathrm{mV} \mathrm{decade}^{-1}$ towards $\mathrm{Cu}$ (II) ion over a wide concentration range of $10^{-6}-10^{-2}$ and $4.9 \times 10^{-7}-1.0 \times 10^{-2} \mathrm{~mol} \mathrm{~L}^{-1}$ with a detection limit of $1.0 \times 10^{-6}$ and $4.9 \times 10^{-7} \mathrm{~mol}$ $\mathrm{L}^{-1}$ at $\mathrm{pH}$ range from $3.0-8.0,3.0-8.5,3.0-8.0$ and $2.5-8.5$ for electrodes I, II, III and IV, respectively. Updated electrodes exhibited a stable and repeatable potential throughout 86, 103, 195 and 205 days for electrodes I, II, III and IV, respectively. The modified electrodes showed strong selectivity for $\mathrm{Cu}$ (II) ion against a large variety of cations. The suggested electrodes were effectively used for the identification of $\mathrm{Cu}$ (II) ion in various samples of water and the produced data were well compared to the results obtained using inductively coupled plasma atomic emission spectrometry (ICP-AAS).

Keywords: $\mathrm{Cu}(\mathrm{II})$-metal-organic frameworks; ionophore; Potentiometeric; copper ions.

\section{FULL TEXT}

(C) 2020 The Authors. Published by ESG (www.electrochemsci.org). This article is an open access article distributed under the terms and conditions of the Creative Commons Attribution license (http://creativecommons.org/licenses/by/4.0/). 